\section{Decomposition of Organic Peroxides}

Is order to study the influence of peroxides on the oxidation of hydrocarbans and to discover the part they play in the phenomenon of ignition, the mode of their decomposition and oxidation is being further investigated. It has been found by Neumann' that diethylperoxide decomposes with luminescence above pressure limits $\left(p_{e}\right)$ which are connected with temperature according to the relation $\log p=A+B / T$. We find that $A$ and $B$ depend on the dimensions of the vessel in which the decomposition occurs. Up to the neighbourhood of the sharp pressure limits the peroxide decomposes unimolecularly with an activation energy $34 \mathrm{kgm}$. cal. The influence of foreign gases (such as helium) on the pressure limits appears to be small, and similar to the behaviour of such gases on the decomposition of azomethane ${ }^{2}$.

E. J. HARRIS.

A. C. Egerton.

Department of Chemical Technology,

Imperial College of Science and Technology.

London, S.W.7.

Feb. 23.

1 C.R., 205, 278 (1937).

${ }^{2}$ Allen and Rice, J. Amer. Chem. Soc., 57, 310 (1935).

Meteoric Ionization in the $E$ Region of the Ionosphere

Is a letter which recently appeared in these columns ${ }^{1}$, T. L. Eckersley described the discovery of great numbers of short-lived ionic clouds in the upper atmosphere. He suggests that the responsible agents might be small meteors or high-speed particles of cosmic origin. His data support the assumption of a meteoric origin so strikingly as to warrant special emphasis.

These clouds appear in the $E$ region of the ionosphere in which meteors are known to spend most of their energy and from which most of the meteoric reflections of radio waves have been obtained. They are apparently short-lived isolated clouds in which momentarily the ionization reaches a value much higher than the average. This is precisely the sort of thing to be expected from the passage of a small meteor. Since a very bright one (-1 mag.) left sufficient ionization to reflect 180 metre waves for 7 minutes after its passage ${ }^{2}$, the short period (of the order of a second) during which reflections are received from these clouds is consistent with their magnitudes. For since there are many more of these clouds than there are meteors as seen by a single observer, the meteors producing them must be fainter than the sixth magnitude on the average.

On the basis of telescopic observations, it has been estimated $^{3}$ that $10^{9}$ meteors (of eighth magnitude or brighter) enter the earth's atmosphere every twentyfour hours. One should thus expect about 180 such meteors in an area $500 \mathrm{~km}$. in diameter in 40 seconds. Eckersley found for these conditions about 30 ionic clouds or $1 / 6$ as many as the estimated number of meteors. The agreement is as good as could be expected considering the nature of the phenomenon.

Even ultra-short waves which are not ordinarily reflected by the ionosphere might be expected to suffer reflection by ionic clouds of meteoric origin. L. F. Jones ${ }^{4}$ has reported observations on such waves which might have this same primary cause. Regarding television signals, which are not ordinarily received with usable field strength at the long distance over which he was working (284 miles), he states : "Sometimes the signal would burst through sharply for a short period ....", and again, "the signal . . reaches momentarily an occasional maximum of great intensity".

Ionic clouds of meteoric origin must be discrete regions in which the ionization is very dense. The rate of recombination would therefore be high and the life of the clouds would be short. This reasoning is consistent with the observed short duration of reflections and again points to the meteoric origin of Eckersley's clouds.

\section{A. M. Skellett.}

Bell Telephone Laboratories, Inc., New York, N.Y. Jan. 11.

1 NATURe, 140, 846 (Nov. 13, 1937).

'Skellett, Proc. I.R.E., 23, 132 (Feb. 1935).

${ }^{3}$ Watson, F., Harvard Tercentenary Papers, No. 32.

- Jones, L. F., Proc. I.R.E., 21, 349 (March 1933).

\section{Disintegration Processes by Cosmic Rays in Plates impregnated with Samarium}

Blau and Wambacher ${ }^{1}$ have recently described experiments in which it appears that a novel type of disintegration may be provoked by cosmic radiation. 'Stars' of tracks due to heavy particles were found in plates which had been exposed for some months at a high altitude. For two years we have been conducting experiments of the same type. We find stars of a similar kind, but there are important differences between our results and those of the Vienna workers, which are indicated below.

The experiments were commenced with the view of discovering whether the cosmic radiation has any influence on the radioactivity of samarium. Ilford $R$ plates were used, and samarium was incorporated into the emulsion by soaking part of the area of each plate in a solution of samarium sulphate. After exposure and development the boundary of the impregnated area is visible on the plate. After preparing a number of plates in this way they were sealed in a small box, along with untreated plates for subsequent comparison. One such box of plates was kept for five months, May-September, at Gulmarg in Kashmir (latitude $34^{\circ}$ N.). A similar box of plates was kept for an equal period in Bombay, being placed in a refrigerator to avoid the deleterious effects of the high temperature. After allowing for the thickness of the packing and the roof of the building, it may be assumed that the Kashmir plates were at an equivalent height of $8,000 \mathrm{ft}$. above sealevel. The Bombay plates were practically at sealevel.

In the first set of experiments carried out in 1936, some stars of tracks were found. The plates, however, were unfortunately rather poor, and we were not able wholly to exclude the possibility of some radio. active contamination. The experiments were therefore repeated in 1937, taking every possible precaution. This time good plates were obtained, which have yielded the following results.

(1) Both in the Bombay and Kashmir plates, we find practically no tracks in the untreated plates, nor in the blank areas of the treated plates. The only tracks found are those due to the natural radioactive content of the glass, such as were described in an earlier paper ${ }^{2}$. This result contrasts with that 